\title{
PERAN SUMBER DAYA MANUSIA DALAM MIGRASI PROGRAM ANALOG KE DIGITAL PADA LPP TVRI KALTENG
}

\author{
Satria Firdaus \\ Email : assyfayumnafirdaus@gmail.com
}

\author{
Pascasarjana Magister Ilmu Komunikasi Uniska Banjarmasin
}

\begin{abstract}
The background of this research was the emergence of International television union policy related to world television migration system from Analog to Digital. It affected to Indonesia which finally released national policy to run the Migration. The purpose of this study was to describe the role of human resource in analog to Digital Migration for Television Media In Lpp Tvri Kalteng.

The research method used was qualitative descriptive with the theories of Perspective, Management, and Communication. The Result of this Research shown that the Role of Human Resource In analog to Digital Migration Program In Television Media In Lpp Tvri Kalteng is very important in the beginning and the end of program operation and its maintenance. In addition, the application of digital program have eased the supervision because in a digital system based on computerized system is very easy and simplifies broadcasting operations by realizing the quality of television especially in LPP Tvri Kalteng.

The implication of this research was as a reference to the world of television in particular Human resources in migration of Analog to Digital technology so that the findings presented in this research could be an input improvement in the process of Digitalization television.
\end{abstract}

Keywords : Human Resource, Analog, Digital.

\section{PENDAHULUAN}

Sumber daya manusia (SDM)

adalah faktor sentral dalam suatu organisasi. Apapun bentuk serta tujuannya, organisasi dibuat berdasarkan berbagai visi untuk kepentingan manusia dan dalam pelaksanaan misinya dikelola dan diurus oleh manusia. Jadi, manusia merupakan faktor strategis dalam semua kegiatan institusi atau organisasi. Selanjutnya, Sumber daya manusia ini harus diatur dan diurus berdasarkan visi organisasi agar tujuan organisasi dapat dicapai secara optimal. Terkait hal ini pelaksanaan program pemerintah terkait alih teknologi yakni dari Analog ke Digital di mana International Telecommunication Union (ITU) atau otoritas Telekomunikasi International telah memberi batas akhir (deadline) kepada seluruh negara di dunia, agar paling lambat, 17 juni 2015 seluruh lembaga Penyiaran melakukan penyiaran secara digital yang barang tentu pada 
akhirnya melibatkan sumber daya manusia dalam beradaptasi dengan teknologi baru ini. Indonesia Sebagai anggota dari International Telecommunication Union ( ITU ) maka mau tidak mau juga mulai melakukan migrasi Analog ke Digital secara bertahap dan di targetkan pada tahun 2018 seluruh wilayah indonesia sudah menggunakan teknologi digital broadcasting ini .

Pelaksanaan program imigrasi teknologi analog ke teknologi digital tengah berjalan khususnya di LPP TVRI Kalteng sejak 2016, hal ini tentu memerlukan Peran sumber daya manusia handal, adaptif, responsif serta profesional dalam perubahan perubahan teknologi, oleh karena itu perlu dilakukan penelitian dalam hal tersebut di atas dengan mengangkat judul thesis:

"PERAN SDM PADA PROGRAM MIGRASI ANALOG KE DIGITAL PADA MEDIA TELEVISI DI LPP TVRI KALTENG “

Berdasarkan latar belakang masalah di atas maka disusun rumusan masalah terhadap penelitian Peran SDM Pada Program Migrasi Analog ke Digital di LPP TVRI Kalteng adalah bagaimana Peran SDM Pada Program Migrasi Analog ke Digital di LPP TVRI Kalteng.
Tujuan dari penelitian ini yaitu untuk mendeskripsikan bagaimana peran SDM di LPP Tvri Kalteng dalam Program Migrasi Analog ke Digital di LPP TVRI Kalteng.

\section{TINJAUAN PUSTAKA}

Metode yang di gunakan dalam penelitian Peran SDM Pada Program Migrasi Analog ke Digital di LPP TVRI Kaltengyaitu Menggunakan Metode Kualitatif dengan Landasan Teori Persepsi . Menurut Wagner dan Hollenbeck (1995), "We human beings have five senses through which experience the world around us: sight, hearing, touch, smell and taste “. Menurutnya, setiap manusia dianugerahi dengan 5 indera yang mana dengan kelima-limanya anda bisa merasakan dunia yang ada di sekitar. Mulai dari penglihatan, pendengaran, penciuman, perasa, serta pengecap . Definisi persepsi menurut Wagner dan Hollenbeck sendiri adalah sebuah proses yang mana seseorang tersebut dapat memilih, mengelola, menyimpan, serta menginterpretasikan informasi-informasi yang telah dikumpulkan melalui kelima indera tersebut.

Teori Komunikasi 
Teori komunikasi adalah satu pandangan dan strategi yang akan membentuk alat kerja dan rangka kerja untuk sesuatu perkara yang hendak di laksanakan dalam proses komunikasi, teori akan membina bentuk kaidah komunikasi yang hendak di buat, terdapat dua aspek utama yang di lihat secara tidak langsung dalam bidang ini sebagai satu bidang pengkajian yang baru. Aspek pertama ialah perkembangan dari beberapa sudut atau kejadian seperti teknologi komunikasi perindustrian dan politik dunia.

Teknologi komunikasi contohnya Radio, Televisi, Telefon, dan Satelit, sementara itu carga dan shield berpendapat bahwa teori komunikasi adalah hubungan di antara konsep teoritikal yang memberi secara keseluruhan maupun sebagian keterangan, penjelasan, penilaian ,maupun perkiraan tindakan manusia berdasarkan komunikator (orang ), yang berkomunikasi ( berbicara, membaca, mendengar, menonton) untuk jangka waktu tertentu melalui media (perantara) Berdasarkan 30 (tiga puluh) macam macam teori komunikasi, menurut para ahli, namun terdapat 5 (lima) teori berhubungan dengan perubahan teknologi yang sangat cepat khususnya yang berhasil peneliti kumpulkan, dalam hal ini pada media Televisi terutama fungsi serta peran yang di sisi lain dapat di golongkan merupakan media komunikasi baru yakni dengan beralihnya sistem penayangan melalui teknologi analog ke digital .

Model komunikasi Lasswell

Paradigma yang di kemukakan Harold Laswell ( 1960 ) dalam karyanya The structure and function of communication in society sering kali di kutip oleh para peminat komunikasi . Laswell mengatakan bahwa cara yang baik untuk menjelaskan komunikasi adalah menjawab pertanyaan sebagai berikut who says what in which channel to whom with what effect ? paradigma Laswell tersebut menunjukan bahwa pada komunikasi terdapat lima unsur di dalamnya . Unsur unsur yang terdapat di dalam komunikasi menurut paradigma lasswell , yaitu

1. Penyampai pesan atau Komunikator Komunikator adalah seseorang yang memberikan pesan kepada komunikan . dalam hal ini seorang komunikator harus mampu mengetahui dan memahami apa yang ingin di sampaikannya kepada komunikan, karena sebuah pesan 
tidak akan sampai dengan baik apabila komunikatornya tidak memahami apa yang ingin disampaikannya.

2. Pesan

Sebuah pesan yang ingin di sampaikan oleh seorang komunikator kepada komunikan harus memiliki makna. Makna tersebut sebaiknya bukan makna yang harus di cerna terlebih dahulu melainkan makna yang mudah di pahami agar dalam berkomunikasi pesan yang ingin di sampaikan komunikator dapat di mengerti oleh komunikan.

3. Media

Sebuah pesan dapat di salurkan menggunakan berbagai macam media . Media yang dapat di gunakan untuk menyalurkan sebuah pesan antara lain udara, televisi, radio, telepon, surat, koran, majalah dan lainnya.

4. Penerima pesan ( Komunikan )

Seorang pengirim pesan sebaiknya mengetahui kepada siapa pesan tersebut ingin di sampaikan , sebuah komunikasi di katakan berhasil jika pesan yang di sampaikan oleh komunikator sampai dan di terima dengan baik oleh komunikan.
5. Efek

Efek atau dampak yang terjadi kepada komunikan setelah menerima pesan yang di sampaikan oleh komunikator.

Media

Kata media berasal dari bahasa latin medius yang secara harfiah berarti “ tengah", "perantara" atau pengantar pesan dari pengirim kepada penerima pesan .Gerlach dan Ely ( 1971 ) mengatakan bahwa media apabila di pahami secara garis besar adalah manusia, materi atau kejadian yang membangun kondisi membuat siswa mampu meperoleh pengetahuan, keterampilan atau sikap, batasan lain telah pula di kemukakan oleh para ahli yang tergabung dalam Association of education and communication technology , 1977 mengungkapkan bahwa media sebagai segala bentuk dan saluran yan di gunakan untuk menyampaikan pesan atau informasi di samping sebagai sistem penyampai atau pengantar ringkasnya Media adalah alat yang menyampaikan atau mengantarkan pesan pesan pembelajaran .

Media saat ini dan jaman dahulu sudah sangat jauh berbeda dan semakin berkembang . Inovasi inovasi terus 
bermunculan dalam perkembangan teknologi media mulai dari surat kabar, radio, televisi dan terakhir internet. khususnya saat ini terdapat beberapa media yang sudah menjadi konsumsi primer yang di gunakan siapa saja

Manajemen Sumber Daya Manusia

Manajemen adalah ilmu dan seni mengatur proses pemanfaatan sumber daya manusia dan sumber sumber daya lainnya secara efektif dan efesien untuk mencapai suatu tujuan tertentu. Manajemen ini terdiri dari enam unsur ( $6 \mathrm{M}$ ) yaitu men, money, method, materials, machines dan market . Unsur men ( manusia ) ini berkembang menjadi suatu bidang ilmu manajemen yang di sebut manajemen sumber daya manusia atau di singkat MSDM yang merupakan terjemahan dari man power management. Manajemen yang mengatur unsur manusia ini ada yang menyebutnya manajemen kepegawaian atau manajemen personalia ( personel management) .

MSDM adalah suatu bidang manajemen yang khusus mempelajari hubungan dan peranan manusia dalam organisasi perusahaan . Unsur MSDM adalah manusia yang merupakan tenaga kerja pada perusahaan, dengan demikian fokus yang di pelajari MSDM ini hanyalah masalah yang berhubungan dengan tenaga kerja manusia saja . Manusia selalu berperan aktif dan dominan dalam setiap kegiatan organisasi, karena manusia menjadi perencana , pelaku dan penentu terwujudnya tujuan organisasi. Tujuan tidak mungkin terealisasi tanpa peran aktif karyawan meskipun alat alat yang di miliki perusahaan begitu canggih .Alat alat canggih milik perusahaan tidak ada manfaatnya, jika peran aktif karyawan di ikut sertakan. Mengatur karyawan adalah sulit dan kompleks , karena mereka mempunyai pikiran , perasaan, status, keinginan, dan latar belakang yang heterogen yang di bawa ke dalam organisasi . Karyawan tidak dapat di atur dan di kuasai sepenuhnya seperti mengatur mesin, modal atau gedung .

Persaingan antar perusahaan di era globalisasi semakin tajam terlebih di 
dalam dunia pertelevisian hingga sumber daya manusia( SDM ) di tuntut untuk terus menerus mampu mengembangkan diri secara proaktif . SDM harus menjadi manusia manusia pembelajar, yaitu pribadi pribadi yang mau belajar dan bekerja keras dengan penuh semangat, sehingga potensi insaninya berkembang maksimal.

Oleh karena itu, SDM yang di perlukan pada saat ini adalah SDM yang sanggup menguasai teknologi dengan cepat, adaptif dan responsif terhadap perubahan tekonologi . dalam kondisi tersebut integritas pribadi semakin penting untuk memenangkan persaingan Agar perusahaan mampu terus bertahan dan bersaing, dominasi teknologi saja tidak cukup jika tidak di tunjang oleh SDM handal sehingga investasi dalam sumber daya ekonomi pun termasuk yang paling berharga, yaitu SDM tidak dapat di pungkiri lagi . Ancaman nyata terbesar terhadap stabilitas ekonomi adalah angkatan kerja yang tidak siap unjtuk menghadapi tantangan tantangan maupun perubahan perubahan yang terjadi di sekelilingnya.

\section{METODE PENELITIAN}

Penelitian ini menggunakan metode kualitatif. Metode kualitatif dianggap efektif untuk mendeskripsikan Peran SDM dalam Program Migrasi Teknologi Analog ke teknologi Digital di LPP TVRI Kalteng juga dalam rangka menyikapi cara cara cepat dan tepat dalam penerapan Migrasi Teknologi Analog ke teknologi Digital di LPP TVRI Kalteng menuju Era Digitalisasi. Menurut Rossi. et al., (1993) Melalui metode penelitian kualitatif akan lebih dapat mengikuti alur peristiwa secara kronologis, menilai sebab akibat dalam lingkup pikiran orang-orang setempat, dan memperoleh penjelasan yang banyak dan bermanfaat. Penggunaan metode kualitatif akan mengungkap fakta 
berdasarkan data dan informasi yang berupa kata-kata dan bukan angka.

\section{HASIL DAN PEMBAHASAN}

Tujuan penelitian ini adalah untuk mendeskripsikan peran SDM pada Program Migrasi Analog ke digital pada media televisi di LPP TVRI Kalteng. Dari hasil penelitian yang telah dilakukan adalah berdasarkan arah dan pola pelaksanaan migrasi ini salah satu bentuk komunikasi formal yang memiliki pola komunikasi Vertikal dimana SDM LPP TVRI se Indonesia untuk menjalankan misi migrasi teknologi Analog switch off menuju suksesnya Digitalisasi penyiaran di LPP TVRI 2018, pola komunikasi vertikal sendiri yakni merupakan pengiriman dan penerimaan pesan di antara level sebuah hirarki, ke bawah dan keatas. Dengan kata lain LPP Tvri sebagai sebuah lembaga penyiaran televisi menerima dan menjalankan keputusan ataupun misi dari pemerintah dalam hal ini kementerian komunikasi dan informasi untuk melakukan migrasi teknologi analog ke teknologi digital dan harus di laksanakan khususnyadi LPP Tvri Se Indonesia tidak terkecuali Lpp Tvri Kalteng .

Hal ini sangat erat hubungannya antara teknologi dan manusia sehingga membutuhkan SDM yang di dalam menjalankan misi nya harus mampu beradaptasi dengan cepat, adaptif serta responsif, sehingga dari kesuksesan program ini, maka Peran SDM sangat memiliki peran penting dalam mewujudkan analog switch off 2018 dan kesuksesan digitalisasi di pertelevisian Indonesia khususnya Lpp Tvri Kalteng. Kaitan antara manusia dengan teknologi begitu erat (Nurudin . 2017 , 25. Perkembangan teknologi komunikasiPT Rajagrafindo persada . Jakarta ). 
Pembahasan dalam Teori dasar komunikasi Harold Lasswell .

Teori Komunikasi Harold Lasswell merupakan teori komunikasi awal ( 1948 ) . lasswell menyatakan bahwa cara terbaik untuk menerangkan proses komunikasi adalah menjawab pertanyaan : who, says what, in which channel, to whom, with what effect ( siapa mengatakan apa melalui saluran apa kepada siapa dengan efek apa ).

Dalam bahasan dapat di sampaikan berdasarkan teori tersebut di atas dengan landasan hasil penelitian .

1. Who ( siapa / sumber )

Dalam kontek ini Who (siapa /sumber) merupakan sumber daya manusia terutama di bidang teknik sub bagian transmisi yang melakukan penyebaran informasi kepada khalayak dalam suatu perangkat teknologi terbarukan yaitu teknologi analog yang akan di ganti ke teknologi digital. Para SDM ini setiap hari melakukan tugasnya dengan mengoperasikan perangkat tersebut ( saat ini kedua transmisiyaitu analog dan digital masih di aktifkan hingga faktor SDM salah satunya siap dalam kontek pengetahuan kedigitalannya tentu yang di tunjang sarana dan prasarana pendukung .

2. Says what

Dalam penyampaian informasi dalam kontek penelitian ini, SDM tadi mengirimkan isi informasi atau pesan yang dapat terekam melalui signal/sinyal berdasarkan gelombang (https://id.m. wikipedia. org> wiki> informasi ) untuk di ketahui migrasi analog ke digital ini salah satunya adalah di mana informasi di bawa sebuah gelombang elektromagnetik hingga sampai ke penerima atau televisi masyarakat namun saat ini gelombang elektromagnetik tersebut di ubah menjadi sinyal digital atau yang di namakan bit hingga berdampak pada keunggulan keunggulan kualitas tayangan. Informasi juga di kelompokan berdasarkan bagaimana format penyajian informasi tersebut misalnya dalam bentuk tulisan , suara, gambar, atau video, jadi di sini yang di maksud dengan isi pesan atau informasi bukan hanya yang bersifat tulisan atau audio bahkan suara namun sinyal dalam bentuk gelombang merupakan salah satu bagian dari isi pesan atau informasi 
3. In which channel

Saluran / media adalah suatu alat untuk menyampaikan pesan dari sumber kepada penerima informasi baik secara langsung (tatap muka) maupun tidak langsung (melalui media cetak / elektronik ). Dalam kontek ini saluran atau media atau alat yang di gunakan yakni perangkat transmisi analog dan digital yang mampu mengirimkan informasi berupa sinyal atau signal dalam bentuk gelombang tadi kepada penerima menuju pesawat televisi ataupun radio.

4. To whom

Seseorang yang menerima, bisa berupa suatu kelompok, individu, organisasi atau suatu Negara yang menerima pesan dari sumber, hal tersebut dapat di sebut tujuan ( destination ), pendengar ( listener), khalayak ( audience ), komunikan, penafsir, penyandi balik ( decoder). untuk kontek penelitian ini para SDM berhasil mengirimkan informasi dalam bentuk sinyal gelombang digital yang bermuatan isi siaran pertelevisian kepada khalayak atau penonton juga pemirsa sehingga khalayak dapat menerima informasi tadi dalam berupa audio ( suara ) serta gambar bergerak ( visual ).

5. With what effect

Dampak atau efek yang terjadi pada penerima informasi setelah menerima pesan dari sumber seperti perubahan sikap dan bertambahnya pengetahuan . Dalam kontek penelitian ini efek yang akan di timbulkan dari keunggulan migrasi teknologi analog ke teknologi digital adalah menyuguhkan kualitas tayangan mulai dari Suara Jernih , Gambar yang bening dengan resolusi tinggi berkualitas DVD dengan gambar stabil meskipun dalam kondisi bergerak ( seperti di dalam mobil ) hingga tidak mudah rentan gangguan cuaca (hujan atau petir), sampai pada tersedianya banyak kanal dalam menyalurkan siaran televisi dan terciptanya efesiensi frekuensi sehingga tercapainya penyampaian informasi penuh jelas dan akurat kepada masyarakat tanpa adanya gangguan secara teknis .

Dengan kata lain, Peran Sumber daya manusia pada program Migrasi Analog ke digital pada media televisi di LPP Tvri Kalteng masih memiliki peran sentral kendati kuantitas bersentuhan secara fisik berkurang karena segalanya 
sudah menggunakan system kerja komputerisasihanya kinerja pengawasan serta pemeliharaan masih menjadi bagian penting pendukung guna terwujudnya kualitas siaran dan materi siaran dapat tersampaikan kepada khalayak menjadi lebih baik di banding teknologi analog, namun semuanya harus di iringi dengan perolehan pengetahuan digitalisasi terhadap SDM secara bertahap menuju pengetahuan digitalisasi secara maksimal.

\section{KESIMPULAN}

1. Peran sumber daya manusia dalam migrasi analog ke digital pada LPP TVRI Kalteng dapat disimpulkan berikut ini :

a. Sumber daya manusia masih menjadi perangkat penting dalam pencapaian tujuan kepentingan besar dari sebuah organisasi sehingga pencapaian keberhasilan tersebut karena di dukung seluruh kerabat kerja / tim kerja bukan karena hasil kerja dari satu / individu atau bidang tertentu saja .

b. Dalam kontek pertelevisian sebuah produksi yang akan menjadi materi siaran atau isi siaran ataupun informasi di kerjakan pada setiap masing masing bidang terutama oleh SDM yang ada di dalamnya khusus untuk setiap SDM pada bidang teknik sub transmisi juga memiliki peran penting dalam memancarkan atau mengirimkan informasi tadi dalam bentuk sinyal / signal gelombang analog maupun digital kepada khalayak sehingga materi siaran atau informasi tadi bisa di lihat secara jelas, di dengar secara bening tanpa harus mendapat gangguan kualitas siaran dari petir ataupun hujan.

c. Informasi di sini dapat berupa isi siaran ataupun materi siaran yang akan di saksikan khalayak, sementara dalam penelitian ini cenderung kepada informasi berupa rekaman yang dapat di transmisikan dan di catat sebagai tanda tanda atau sebagai sinyal berdasarkan gelombang .https://id.m.wikipedia.org>wiki> informasi

d. Untuk sumber pengirim pesan lebih mengarah kepada SDM yang berada pada seksi bidang teknik sub transmisi di mana di situ terdapat perangkat transmisi 
Analog dan Digital di mana materi siaran akan di kirimkan melalui perangkat transmisi analog atau digital ke khalayak melalui pesawat televisi.

e. Keunggulan teknologi digital pada akhirnya membawa kelebihan di banding teknologi analog yang di operasionalkan para SDM di LPP Tvri Kalteng khususnya di mana materi siaran atau isi siaran yang di bawa sinyal dalam bentuk gelombang digital tadi mampu mewujudkan melalui gambar yang cerah / bersih, suara yang bening hingga tidak rentan oleh gangguan gangguan hujan dan petir .

\section{Saran}

Berdasarkan pengalaman penulis dalam melakukan penelitian maka penulis memberikan saran sebagai berikut:

a. LPP TVRI harus menggiatkan pendidikan dan pelatihan Dasar Lanjutan digital dan mengkuotakan setiap SDM dari masing masing LPP TVRI daerah lebih dari 2 orang minimal 2 orang , sehingga mempercepat peningkatan kualitas
SDM LPP TVRI se Indonesia jauh lebih baik .

b. LPP TVRI Kalteng dapat mendatangkan Instruktur Digital guna memberikan pencerahan sebagai tambahan pengetahuan tentang digital kepada Setiap SDM .

c. Perekrutan atau pengadaan karyawan baru harus sudah di lakukan jauh hari agar mampu tersosialisasi dengan lebih lama sehingga di harapkan proses seleksi tenaga kerja banyak mendapatkan referensi serta yang terbaiklah yang di pilih sesuai dengan kebutuhan Lembaga dalam hal ini tenaga kerja yang memiliki dasar dasar ilmu teknologi yang baik.

d. Migrasi ke Sistem Penyiaran TV Digital tidak dapat dihindari, karena cepat atau lambat seluruh dunia akan beralih ke TV Digital.

e. Stasiun TV khususnya LPP TVRI se Indonesia perlu menyatukan visi dalam kapan menentukan jadwal analog switch off untuk masingmasing Stasiunnya, serta membuat Road map atau blue print pemanfaatan kelebihan dari Digital ini . karena nantinya setiap Stasiun LPP Tvri memiliki banyak channel untuk mengisinya dengan ragam materi siaran . 
f. Mensosialisasikan program migrasi ini selain melalui program-program TV / keberadaan media social pun dapat di manfaatkan serta program program kemasyarakatan seperti pada ajang car free day di mana masyarakat terpusat di satu pusat tertentu .

g. Koordinasi dan sinergi antar Stasiun TV baik dalam maupun luar negeri, juga pemerintah khususnya kementerian terkait juga dengan pihak-pihak yang terkait lainnya untuk terlaksananya peralihan teknologi analog ke digital secara perlahan namun pasti .

h. Dalam rangka peningkatan SDM menuju digitalisasi yang sudah mulai berproses saat ini ,SDM LPP TVRI Kalteng juga di kirim untuk mengikuti pendidikan dan pelatihan dasar transmisi digital di LPP TVRI Nasional, sementara bagi SDM LPP TVRI Kalteng yang belum memperoleh kesempatan diklat dasar transmisi digital tetap akan menerima pengetahuan tersebut sepulangnya teman SDM yang sudah mengikuti diklat ( sharing knowledge ) tentang kedigitalan .

i. Waktu pelaksanaan Pelatihan dan pendidikan dasar transmisi digital di pandang masih belum maksimal karena dalam setahun hanya di laksanakan satu kali dengan jumlah SDM dari satuan LPP TVRI Daerah se indonesiayang hanya satu orang. Oleh karena itu perlu diadakan peningkatan kuantitas dalam pelatihan dan pendidikan juga jumlah peserta yang dikirim.

j. Keberadaan tenaga listrik yang ada di Kalimantan tengah juga mempengaruhi operasional Pemancar ataupun siaran, karena kerapnya di lakukan pemadaman listrik dan hal tersebut akhirnya lambat laun mengurangi kualitas pemancar serta perangkat teknologi lainnya. Oleh karena itu diperlukan adanya pasokan listrik yang lebih maksimal agar menjamin kelancaran dan kualitas penyiaran.

\section{DAFTAR PUSTAKA}

Bajari , Atwar . 2015 . Metode Penelitian Komunikasi Prosedur , Tren dan Etika. Simbiosa rekatama Media, Bandung

Damayani , Agustini Ninis , Karimah , El Kismiyati , sumarno . 2015. Filsafat dan etika Komunikasi .Universitas Terbuka, Banten

Fidler, robert .1997 . Mediamorphosis : Understanding new media.California : Pine Forge Press 
Hubeis , Aida Vitayala dkk . 2015. Komunikasi Inovasi . Universitas terbuka, Banten

Hasibuan , S.P Malayu . 2017 . Manajemen Sumber Daya Manusia . Bumi aksara

Kuswarno , Engkus , Rusmana Agus .2012 . Analisa Sistem Informasi . Universitas Terbuka, Banten

Kriyantoro , Rachmat . 2006 . Teknik Praktis Riset Komunikasi . Kencana Prenadamedia Group , Jakarta

Littlejohn, stephen W dan foss, Karen A . 2008 . Teori komunikasi ( theories of human

communication ) . Salemba Humanika, Jakarta

Mulyana , Deddy . 2008 . Ilmu Komunikasi suatu pengantar . PT . Remaja Rosdakarya, Bandung

Mangkunegara, Anwar prabu . 2015. Manajemen Sumber daya manusia perusahaan . PT. Remaja Rosdakarya , Bandung

Nurudin . 2017 . Perkembangan Teknologi Komunikasi . Rajawali pers, Jakarta

Nasution , Zulkarimen . ( 1995a ). Komunikasi Inovasi . Universitas Terbuka, Jakarta

Nasution , Zulkarimen . ( 1995b ). Perencanaan Program Komunikasi . Univeristas terbuka, Jakarta

Panuju , redi .2015 . Sistem Penyiaran Indonesia . PT . Kharisma Putra Utama, Jakarta

Rakhmat, jalaluddin . 2011 . Psikologi Komunikasi . PT Remaja Rosdakarya, Bandung

Severin, J Werner dan Tankard jr , James W .2001 .Teori Komunikasi : Sejarah, Metode, dan Terapan di dalam Media Massa. Kencana Prenadamedia Group, Jakarta
Setiawan, Bambang Dkk .2007 . Metode Penelitian Komunikasi. Universitas Terbuka, Banten

Sutrisno, Edy . 2016 . Manajemen Sumber Daya Manusia . Kencana Prenadamedia group, Jakarta

www . Kompasiana .com / Rahmat gempol / Selamat-datang-Televisi -Digital - di -Indonesia denontarr.blogspot.co.id/2008/11/ perspektif-komunikasi-b-aubreyfisher.html

https://id.wikipedia.org/wiki/media.analo g.dan digital

https://www.scribd.com/doc/58415610 analog-digital-converter

https://Perkembangan Teknologi.Wordpress.com https://kominfo.go.id/content/detail/1715 /menkominfo-ayo-pindah-ke-tvdigital

hhtps://perkembanganteknologi.wordpre ss.com

minecybermedia.blogspot.co.id/2015/12/ konvergensi-media.html

Larasmaharani.blogspot.co.id/2014/04/p erbedaan-teknologi-analog-dan html

Agungsuryalesmana.blogspot.co.id/2015 /03/Perkembangan-Teknologianalog-dan html

http://www.emeraldinsight.com/doi/full/ 10.1108/IJCMA-02-2016-0006/ Understanding Top Management Team Conflict. Diakses pada 23 Desember 2017. 